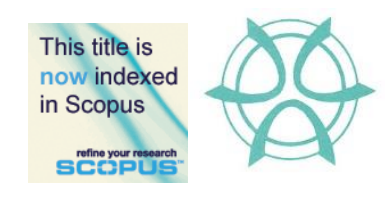

PLANNING MALAYSIA:

Journal of the Malaysian Institute of Planners

VOLUME 17 ISSUE 2 (2019), Page 203 - 214

\title{
CHILDREN'S DIRECT AND INDIRECT EXPERIENCES WITH NATURE AND THEIR CONNECTEDNESS TO NATURE
}

\author{
Nor Diyana Mustapa ${ }^{1}$, Nor Zarifah Maliki ${ }^{2}$, Nor Fadzila Aziz ${ }^{3}$ \& Aswati Hamzah ${ }^{4}$ \\ ${ }^{1}$ Faculty of Architecture and Ekistics \\ UNIVERSITI MALAYSIA KELANTAN \\ ${ }^{2,3}$ School of Housing, Building and Planning \\ UNIVERSITI SAINS MALAYSIA \\ ${ }^{4}$ School of Educational Studies \\ UNIVERSITI SAINS MALAYSIA
}

\begin{abstract}
Direct experiences with nature during childhood plays an important role to influence children's connectedness to nature (CTN) as a child now and later as an adult. However, today's children obtain nature experiences mostly through indirect ways (e.g. observing nature and vicarious learning), which may not have the same quality as direct ways (e.g. activities with plants and earth elements). Hence, this study aims to first identify the current trends of children experience nature and further examine the effects of both direct and indirect experiences with nature on their CTN. Questionnaires were distributed to 760 children from 20 schools include both urban and rural schools in Kedah and Penang, Malaysia. The data were analysed using mean score, standard deviation, and multiple regression. The results confirmed that the current trends of children having experiences with nature are more through indirect ways. Results also showed that indirect experiences with nature make more contribution to children's CTN than direct experiences. Overall, this study highlights that indirect experiences with nature can be an alternative and effective way to develop children's CTN without neglecting the importance of direct experiences with nature.
\end{abstract}

Keywords: children, connectedness to nature, direct experiences with nature, indirect experiences with nature 
Nor Diyana Mustapa, Nor Zarifah Maliki, Nor Fadzila Aziz, \& Aswati Hamzah

Children's Direct and Indirect Experiences with Nature and their Connectedness to Nature

\section{INTRODUCTION}

An individual attachment to nature, known as connectedness to nature (CTN), plays an important role in developing a positive attitude and behaviour towards the environment. Studies have found that CTN has positively influenced people's environmental concerns and behaviours (Cheng \& Monroe, 2010; Collado, Staats, \& Corraliza, 2013; Duerden \& Witt, 2010), as well as specific attitudes towards nature (Lin et al., 2017) and the environment including wildlife (Zhang, Goodale, \& Chen, 2014). In addition, CTN also has a positive impact on individual's psychological well-being (Capaldi, Dopko, \& Zelenski, 2014; Howell, Dopko, Passmore, \& Buro, 2011). Given the many benefits of CTN regarding individual attitudes towards nature and the environment, as well as psychological well-being, the question is how an individual develops their CTN. Many studies have demonstrated that frequent experiences with and in nature are the most significant factor that contributes to an individual's CTN, which subsequently influences their environmental concerns and behaviours (Cheng \& Monroe, 2010; Duerden \& Witt, 2010; Zhang et al., 2014). Most importantly, retrospective studies have found that childhood frequent experiences with and in nature in creating long-lasting effects that endure until adulthood (Chawla, 2007; Wells \& Lekies, 2006).

However, it has become a concern as the frequency of children having direct experiences with nature is declining (Gundersen, Skår, O'Brien, Wold, \& Follo, 2016; Skår \& Krogh, 2009). Rapid urbanisation and population growth, which mostly occur in developing countries including Malaysia, have reduced children's experiences with nature especially direct experiences (Chawla \& Derr, 2012; Louv, 2008). Modernisation has also caused children's leisure activities to change from them being actively involved in outdoor activities to being passively confined to indoor activities, aided by gadgets (Louv, 2008; Veitch, Bagley, Ball, $\&$ Salmon, 2006). Also, parental restrictions due to safety have limited children's opportunities to play in the outdoor environment (Castonguay, 2010; Holt, Lee, Millar, \& Spence, 2015) where they can experience nature directly. For that reason, children have obtained experiences with nature mostly from indirect experiences through the media (Cohen \& Horm-Wingerd, 1993; Kellert, 2005) and books, as well as in classes and visits to organised natural places, such as zoos (Louv, 2008).

Even though many studies have demonstrated that both direct and indirect experiences with nature make contribution to children's CTN (Duerden $\&$ Witt, 2010), concerns have been raised, as several studies have found that children have less knowledge about, affection to and interest in nature when they only have indirect experiences with nature without direct experiences (Aaron \& Witt, 2011). Direct experiences with nature through gardening and planting trees were found to make greater contribution to children's CTN when they become adult as compared to indirect experiences with nature (Lohr \& Pearson-mims, 
PLANNING MALAYSIA

Journal of the Malaysia Institute of Planners (2019)

2005). As the frequency of children having direct experiences with nature is declining (Skår \& Krogh, 2009; Gundersen et al., 2016) and children obtain nature experiences mostly through indirect ways; hence, it is important to examine whether indirect experiences with nature have a similar effect to direct experiences with nature on children's CTN. Moreover, most studies have been conducted in Western countries, and few have been conducted in Asian countries. It is important to fill this gap because studies have found that people with different cultures have a different engagement with nature (Milfont, 2012; Robertson, Walford, \& Fox, 2003). Therefore, this study aims to first identify the current trends of Malaysian children experience with nature that include both direct and indirect experiences, and further examine the effects of these experiences on their CTN.

\section{METHODOLOGY}

\section{Participants}

This study used quantitative approach involving distribution of questionnaires to 760 children aged 10-11 years old from 20 schools, both urban and rural schools, located in Northern Region of Malaysia, particularly in Kedah and Penang. The sample was chosen using stratified random sampling. Children aged 10 to 11 years old were first divided into urban and rural strata. Then, five schools were selected randomly from each stratum; all the selected schools were national schools (Sekolah Kebangsaan (SK)). Subsequently, a class was randomly chosen from each batch (year) in every school. Complete collection (criterion sampling) was used to select the children. Every student in the chosen classes completed the questionnaire; however, only 760 were randomly selected according to the number that had been calculated using proportionate simple random sampling calculation. Overall the number of selected children was 382 from Kedah and 378 from Penang. Data collection was conducted from February 2016 until April 2016. Copies of questionnaire were distributed personally to the children in classes. The questionnaires were distributed in the Malay language as English is not the first language of the children. The children took 20 minutes to answer the questionnaire.

\section{Questionnaire Development}

Experiences with Nature

Children's experiences with nature were measured through two types of experiences, which were 'direct experiences' and 'indirect experiences'. The items for both experiences were adapted from Cheng and Monroe (2010), and Zhang et al. (2014). Some of the items were also derived from pre-test. The children were asked to tick on the frequency of them doing the listed items. 
Nor Diyana Mustapa, Nor Zarifah Maliki, Nor Fadzila Aziz, \& Aswati Hamzah

Children's Direct and Indirect Experiences with Nature and their Connectedness to Nature

Following Cheng and Monroe (2010), this study employed five-point Likert scale ( $1=$ never, $2=$ seldom, $3=$ sometimes, $4=$ often and $5=$ =very often). 'Seldom' refers to 1 to 2 times per year, 'sometimes' refers to almost every month, 'often' refers to almost every week and 'very often' refers to almost every day.

'Direct experiences' was measured by 22 items that have been categorised into activities with plants, activities with earth elements, water activities, and activities with animals. Activities with plants category consists of eight items, for example, climbing trees, picking flowers, and gardening. Activities with earth elements category includes three items which are playing with soil, playing with mud, and collecting sea shell. Water activities category consists two items: bathing at the beach and bathing in the river. Meanwhile, activities with animals category consists of nine items, for example, fishing and catching butterfly.

'Indirect experiences' was measured by 12 items that have been categorised into three categories: observation of natural elements, visit organised natural places, and vicarious activities. Observation of natural elements category consists of six items, such as observing plants, observing birds, and observing insects. Visits to organised natural places category consists of three items: visiting zoo, visiting aquaria centre, and visiting botanical garden. Vicarious activities category consists of three items: watching nature programme on television, reading books about nature, and collecting nature pictures.

The reliability test indicated that Cronbach's alpha coefficient values for direct and indirect experiences with nature were acceptable with values ranging from 0.7 to 0.8 .

\section{Connectedness to Nature}

Children's CTN was measured through six constructs, which were nature dependence, sense of responsibility, enjoyment in nature, empathy towards nature, interest in nature activities, and interest in natural spaces. Overall, there were 26 items and the items for each construct were adapted from previous instruments of CTN. The items were a combination of items from studies by Nisbet, Zelenski and Murphy (2008), Clayton (2003), Larson, Green and Castleberry (2009), Cheng and Monroe (2010), Aaron and Witt (2011), McAllister, Lewi and Murphy (2012), and Ballantyne and Packer (2002). The level of agreement for children's CTN was designed to be child friendly by using a smiley icon to indicate their level of agreement. This present study measured CTN using a four-point Likert scale with 1 (strongly disagree), 2 (disagree), 3 (agree), and 4 (strongly agree).

Nature dependence was measured through five items. The examples of the items for nature dependence were, "Nature is important for my life" and "I need nature to survive". Meanwhile, sense of responsibility was constructed by six items and the examples of items were "I will take care of nature". Empathy 
PLANNING MALAYSIA

Journal of the Malaysia Institute of Planners (2019)

towards nature was measured by three items. The items for empathy towards nature were "I feel sad seeing forests being cleared" and "I feel sad seeing nature being destroyed". Enjoyment in nature was measured through eight items. The examples of items for enjoyment in nature was "I feel happy being in natural places such as waterfalls, rivers, and the beach". For interest in natural spaces, six items were used to measure children's intention to be in spaces that have natural elements. Examples of items for this construct were "I want to own a house that has green areas" and "I would prefer to live in a house surrounded by green areas compared to surrounded by buildings". As for interest in nature activities, four items were used to measure children's interest in being involved in nature activities. Examples of items for interest in nature activities was "I want to join in camping near natural places".

A pilot study was first conducted before the actual study to ensure the children understand the questionnaire. Face, content, and construct validity were also conducted to validate the instrument. As for reliability test, this study used 0.6 as the cut-off for Cronbach's alpha value, as the instrument in this study was a newly developed instrument. The results for reliability test indicated that the CTN scale was reliable with values of Cronbach's alpha for each construct ranging from 0.6 to 0.9 . Even though five of the constructs have an acceptable value with a low value for Cronbach's alpha (0.6), for all items, the intercorrelation values were above 0.3 which were acceptable (Pallant, 2013).

\section{Analyses}

The data were analysed using IBM SPSS Statistics Version 22. Descriptive analysis using mean score and standard deviation were used to identify the frequency of both direct and indirect experiences with nature. Meanwhile, inferential analysis using standard multiple regression was used to examine the relationship between children's direct and indirect experiences with nature and their CTN.

\section{RESULTS}

\section{Frequency of Children's Direct and Indirect Experiences with Nature}

Based on Figure 1, it is apparent that indirect experiences in nature have the highest mean score for all for locations, followed by direct experiences in nature. These findings indicate that the children involved more with indirect experiences with nature as compared to direct experiences. 
Nor Diyana Mustapa, Nor Zarifah Maliki, Nor Fadzila Aziz, \& Aswati Hamzah

Children's Direct and Indirect Experiences with Nature and their Connectedness to Nature

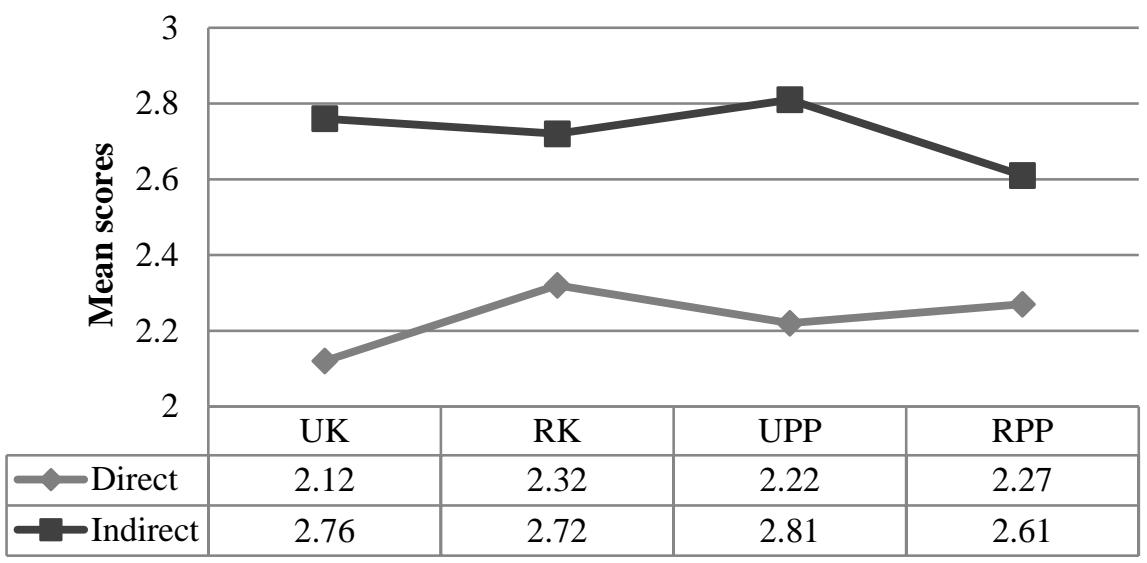

Legend: UK=Urban Kedah, RK=Rural Kedah, UPP=Urban Penang, RPP=Rural Penang

Figure 1 Mean scores for direct and indirect experiences with nature

\section{Direct Experiences with Nature}

As shown in Figure 2, it is clear that the children frequently engaged in activities with plants for all locations with mean score of $2.56(\mathrm{SD}=0.77), 2.69(\mathrm{SD}=0.73)$, $2.65(\mathrm{SD}=0.76)$ and $2.63(\mathrm{SD}=0.73)$, respectively for Urban Kedah, Rural Kedah, Urban Penang and Rural Penang. This is followed by activities with water elements, activities with animals, and activities with earth elements. These results indicate that children from all locations have about the same frequency of direct experiences for all activities with just slight differences.

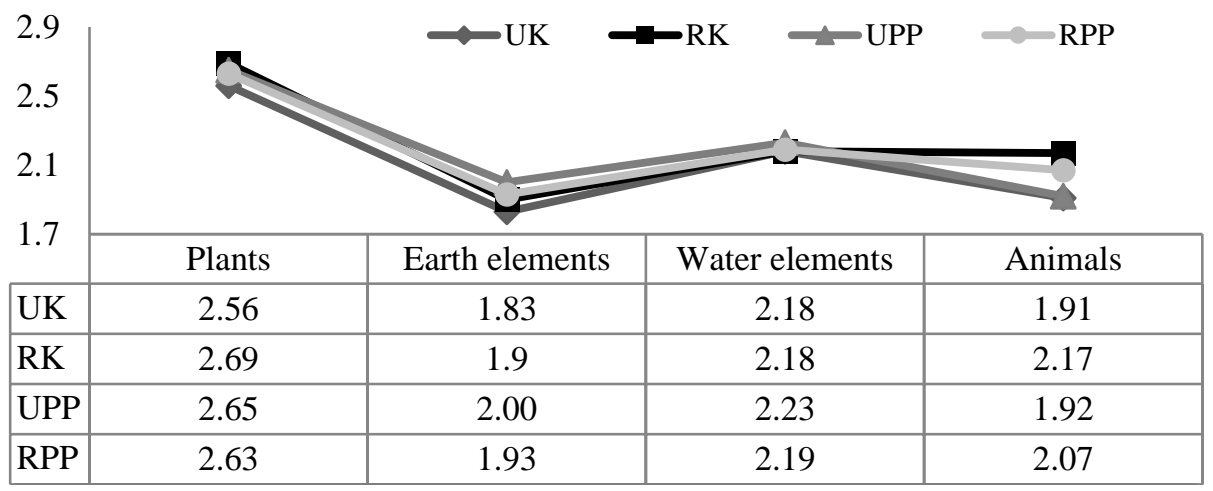

Legend: UK=Urban Kedah, RK=Rural Kedah, UPP=Urban Penang, RPP=Rural Penang

Figure 2 Mean scores for each category of direct experiences with nature 
PLANNING MALAYSIA

Journal of the Malaysia Institute of Planners (2019)

\section{Indirect Experiences with Nature}

From Figure 3, it is clear that the activities that have higher mean scores for indirect experiences are observation of natural elements and vicarious activities. Meanwhile, the least frequent indirect experiences with nature that children did was visit organized natural places. These results indicate that the activities that the children did most are observation of natural elements and vicarious activities. However, the category of visits to organised natural places has a lower frequency, as children need to travel to those places.

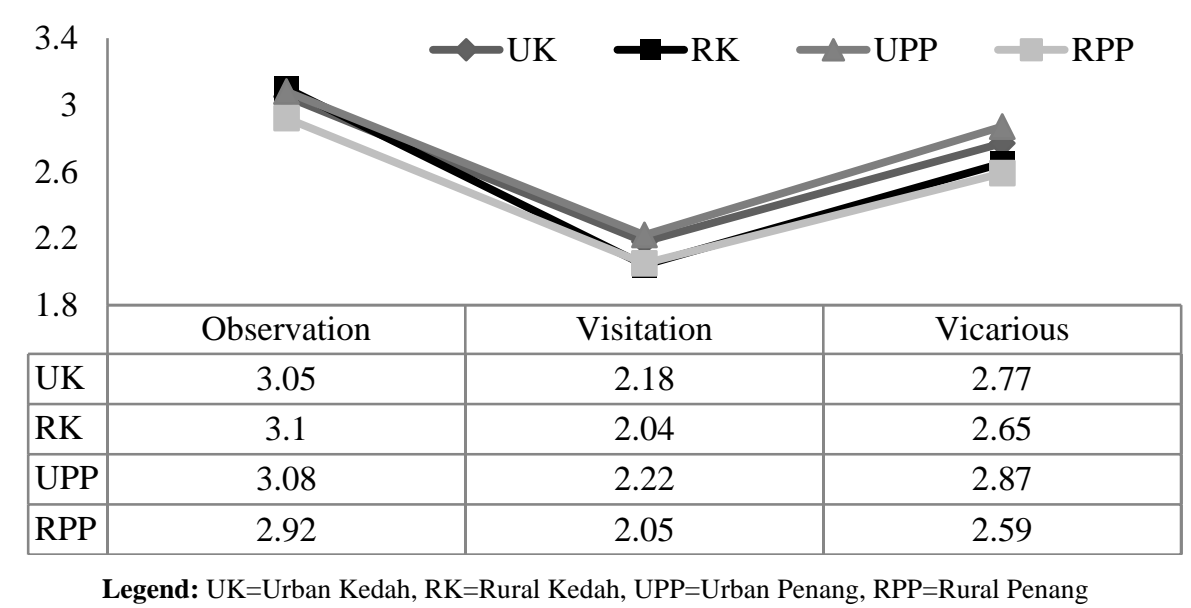

Figure 3 Mean scores for indirect experiences with nature categories

The Relationship between Children's Experiences with Nature and their Connectedness to Nature

Prior to conducting multiple regression analysis, all the preliminary analyses for multicollinearity, outliers, normality, linearity, and homoscedasticity meet the assumptions; hence, the regression model is appropriate. The coefficient determination for the developed model is $0.120(\mathrm{R} 2=0.120)$. Thus, 0.120 $(12.0 \%)$ of CTN can be explained by the independent variables. The model has a significance level of $0.000(\mathrm{p}<0.005)$. Therefore, this model is appropriate to predict CTN. Based on Table 2, only one independent variable predicts CTN. The results illustrate that indirect experiences with nature are statistically significant in making a contribution to CTN with $p<0.05(b=0.32, t=7.74$, Sig. 0.00). Meanwhile, direct experiences with nature is not statistically significant in making a contribution to CTN with $(b=0.044, t=1.06$, Sig. 0.29). Surprisingly, the results have demonstrated that direct experiences with nature have no significant effect on CTN, whereas indirect experiences with nature significantly affect CTN. 
Nor Diyana Mustapa, Nor Zarifah Maliki, Nor Fadzila Aziz, \& Aswati Hamzah

Children's Direct and Indirect Experiences with Nature and their Connectedness to Nature

Table 2 Regression coefficients (direct and indirect experiences)

\begin{tabular}{lccc}
\hline \multicolumn{1}{c}{ Model } & $\begin{array}{c}\text { Standardized } \\
\text { Coefficients }\end{array}$ & $\mathbf{t}$ & \\
\cline { 2 - 3 } & Beta & & Sig. \\
\hline (Constant) & & 51.50 & .000 \\
\hline Direct & .044 & 1.06 & .291 \\
\hline Indirect & .322 & 7.74 & .000 \\
\hline
\end{tabular}

\section{Direct Experiences with Nature and Connectedness to Nature}

The results indicate that the model is appropriate, with a significant level of 0.00 $(\mathrm{p}<0.005)$. As shown in Table 3, activities with plants and activities with earth elements are statistically significant in predicting CTN, whereas activities with water elements and activities with animals are statistically insignificant in predicting CTN. The highest predictor in making a contribution to CTN that has the highest beta coefficient is activities with plants with $\mathrm{p}<0.05(\mathrm{~b}=0.23, \mathrm{t}=5.50$, Sig. 0.000). The second highest predictor is activities with earth elements with $\mathrm{p}$ $<0.05(\mathrm{~b}=0.06, \mathrm{t}=3.12$, Sig. 0.002).

Table 3 Regression coefficients (direct experiences activities)

\begin{tabular}{lccc}
\hline \multicolumn{1}{c}{ Model } & $\begin{array}{c}\text { Standardized } \\
\text { Coefficients }\end{array}$ & $\mathbf{t}$ & \\
\cline { 2 - 3 } & Beta & & Sig. \\
\hline (Constant) & & 53.59 & .000 \\
\hline Plants & .227 & 5.50 & .000 \\
\hline Earth elements & .121 & 3.12 & .002 \\
\hline Water elements & .037 & .97 & .332 \\
\hline Animals & -.057 & -1.36 & .176 \\
\hline
\end{tabular}

Indirect Experiences with Nature and Connectedness to Nature

The model has a significance level of 0.000 ( $p<0.005)$. Hence, the model of indirect experiences with nature is appropriate to predict CTN. As shown in Table 4, observation of natural elements and vicarious learning activities are statistically significant in predicting CTN. Vicarious activities have the highest beta coefficient (see Table 4.43); thus, vicarious activities make the strongest contribution to CTN with $\mathrm{p}<0.05(\mathrm{~b}=0.28, \mathrm{t}=7.58$, Sig. 0.000$)$, followed by observation activities with $\mathrm{p}<0.05(\mathrm{~b}=0.15, \mathrm{t}=4.16$, Sig. 0.000$)$. 
PLANNING MALAYSIA

Journal of the Malaysia Institute of Planners (2019)

Table 4 Regression coefficients (indirect experiences activities)

\begin{tabular}{lccc}
\hline \multicolumn{1}{c}{ Model } & $\begin{array}{c}\text { Standardized } \\
\text { Coefficients }\end{array}$ & & Sig. \\
\cline { 2 - 2 } & Beta & $\mathbf{t}$ & .000 \\
\hline (Constant) & & 59.68 & .000 \\
\hline Observation & .152 & 4.16 & .270 \\
\hline Visits & .039 & 1.10 & .000 \\
\hline Vicarious & .281 & 7.58 & \\
\hline
\end{tabular}

\section{DISCUSSION}

In general, as expected, the mean scores for direct experiences is lower than indirect experiences with nature, indicating that the current trend is children having more indirect experiences with nature compared to direct experiences. As for direct experiences with nature, the most frequent activities that the children involved is activities with plants. Meanwhile, for indirect experiences with nature, the most frequent activities that the children involved are observation of natural elements and vicarious activities. Unexpectedly, this study found that direct experiences is insignificant predictor of children's CTN, while indirect experiences is significant. This finding is in contrast to substantial studies that have suggested that direct experiences have positive effects on children's CTN (Cheng \& Monroe, 2010; Duerden \& Witt, 2010; Zhang et al., 2014). This finding is also in contrast to Lohr and Pearson-mims's (2005) study that found direct experiences make greater contribution to CTN than indirect experiences with nature. On the other hand, although indirect experiences with nature do not provide the adventure, surprise, and discovery element, they do significantly affect children's CTN. These findings can be explained by the fact that the quality of direct experiences that the children are having are insufficient to develop their knowledge on, affection to, and interest in nature. Another possible explanation might be related to cultural differences, as people in different cultures engage differently with nature, as has been found in several studies (Milfont \& Sibley, 2012; Robertson et al., 2003).

For indirect experiences with nature, further analysis has shown that experiences through observation and vicarious activities significantly predict CTN, with vicarious activities make a slightly greater contribution compared to observation. This finding is in contrast to findings of previous studies where children who had indirect experiences with nature through vicarious activities, such as books and media, were unaware about and not connected to nature (Aaron $\&$ Witt 2011). A possible explanation of why vicarious activities contribute to children's CTN may relate to the knowledge that they obtain through vicarious learning activities, which helps to increase their understanding on the importance of nature and develop their sense of responsibility and empathy towards nature; these further affect their overall CTN. Furthermore, this finding suggests that only being surrounded by nature, which allows children to have daily view and 
Nor Diyana Mustapa, Nor Zarifah Maliki, Nor Fadzila Aziz, \& Aswati Hamzah

Children's Direct and Indirect Experiences with Nature and their Connectedness to Nature

observation towards nature, also can help to increase the level of children's CTN. Therefore, indirect experiences can be an alternative and effective way to develop children's CTN.

As for direct experiences with nature, even though direct experiences do not significantly affect children's CTN, further analysis revealed that activities with plants and earth elements are statistically significant in making a slight contribution to children's CTN. This indicates that as children frequently do activities with plants and earth elements such as gardening and playing with soil, the children will gain more knowledge about the plants and soil, develop affection towards those elements and further develop their interest to further participate in activities that involve those elements. Both activities make only a small contribution, something which is likely to be related to the quality of the experience itself. Hence, the importance of direct experiences also cannot be neglected.

\section{CONCLUSION}

Overall, the findings of this research suggest that such low frequency of children's direct experiences with nature is insufficient to develop their CTN; and the trends of children having most nature experiences indirectly does not give negative effect as indirect experiences with nature is significantly influence their CTN. Hence, indirect experiences through vicarious activities and observation towards nature can become an effective alternative way to connect the children with nature in the future as children have constraints of being explorative in the outdoor environment where they can have direct experiences with nature. However, the importance of direct experiences with nature cannot be neglected. It is suggested that practitioners in built environment, environmental education, as well as parents should help to reconnect the children with nature through both direct and indirect ways as both can complement each other.

\section{ACKNOWLEDGEMENTS}

The author would like to acknowledge the Fundamental Research Grant Scheme (FRGS) under the Ministry of Education (MOE) as the funding for this research.

\section{REFERENCES}

Aaron, R. F., \& Witt, P. A. (2011). Urban students' definitions and perceptions of nature. Children Youth and Environments, 21(2), 145-167.

Ballantyne, R., \& Packer, J. (2002). Nature-based excursions: School students' perceptions of learning in natural environments. International Research in Geographical and Environmental Education, 11(3), 218-236.

Capaldi, C. A., Dopko, R. L., \& Zelenski, J. M. (2014). The relationship between nature connectedness and happiness: A meta-analysis. Frontiers in Psychology, 5(2014), 1-17.

Castonguay, G. (2010). Children's use of the outdoor environment in a low-income 
Montreal neighborhood. Children, Youth and Environments, 20(1), 200-230.

Chawla, L. (2007). Childhood experiences associated with care for the natural world: A theoretical framework for empirical results. Children, Youth and Environments, 17(4), 144-170.

Chawla, L., \& Derr, V. (2012). The development of conservation behaviours in childhood and youth. In S. Clayton (Ed.), The Oxford handbook of environmental and conservation psychology (pp. 527-555). New York: Oxford University Press.

Cheng, J. C.-H., \& Monroe, M. C. (2010). Connection to nature: Children's affective attitude toward nature. Environment and Behavior, 44(1), 31-49.

Clayton, S. (2003). Environmental identity: A conceptual and an operational definition. In S. Clayton \& S. Opotow (Eds.), Identity and the natural environment: The psychological significance of nature (pp. 45-65). Cambridge, MA: MIT Press.

Cohen, S., \& Horm-Wingerd, D. (1993). Children and the environment: Ecological awareness among preschool children. Environment and Behavior, 25(1), 103120.

Collado, S., Staats, H., \& Corraliza, J. A. (2013). Experiencing nature in children's summer camps: Affective, cognitive and behavioural consequences. Journal of Environmental Psychology, 33(2013), 37-44.

Duerden, M. D., \& Witt, P. A. (2010). The impact of direct and indirect experiences on the development of environmental knowledge, attitudes, and behavior. Journal of Environmental Psychology, 30(4), 379-392.

Gundersen, V., Skår, M., O’Brien, L., Wold, L. C., \& Follo, G. (2016). Children and nearby nature: A nationwide parental survey from Norway. Urban Forestry and Urban Greening, 17, 116-125.

Holt, N. L., Lee, H., Millar, C. A., \& Spence, J. C. (2015). 'Eyes on where children play': A retrospective study of active free play. Children's Geographies, 13(1), 73-88.

Howell, A. J., Dopko, R. L., Passmore, H.-A., \& Buro, K. (2011). Nature connectedness: Associations with well-being and mindfulness. Personality and Individual Differences, 51(2), 166-171.

Kellert, S. R. (2005). Building for life: Designing and understanding the human-nature connection. Washington, DC: Island Press.

Larson, L. R., Green, G. T., \& Castleberry, S. B. (2009). Construction and validation of an instrument to measure environmental orientations in a diverse group of children. Environment and Behavior, 43(1), 72-89.

Lin, B. B., Gaston, K. J., Fuller, R. A., Wu, D., Bush, R., \& Shanahan, D. F. (2017). How green is your garden?: Urban form and socio-demographic factors influence yard vegetation, visitation, and ecosystem service benefits. Landscape and Urban Planning, 157, 239-246.

Lohr, V. I., \& Pearson-mims, C. H. (2005). Children's active and passive interactions with plants inflence their attitudes and actions towards trees and gardening as adults. HorTechnology, 15(3), 472-476.

Louv, R. (2008). Last children in the woods. Saving our children from nature-deficit disorder. Chapel Hill, NC: Algonquin Books.

McAllister, C., Lewis, J., \& Murphy, S. (2012). The green grass grew all around: Rethinking urban natural spaces with children in mind. Children, Youth and Environments, 22(2), 164-193. 
Nor Diyana Mustapa, Nor Zarifah Maliki, Nor Fadzila Aziz, \& Aswati Hamzah

Children's Direct and Indirect Experiences with Nature and their Connectedness to Nature

Milfont, T. L. (2012). Cultural differences in environmental engagement. In S. Clayton (Ed.), The Oxford handbook of environmental and conservation (pp. 181-200). New York: Oxford University Press.

Milfont, T. L., \& Sibley, C. G. (2012). The big five personality traits and environmental engagement: Associations at the individual and societal level. Journal of Environmental Psychology, 32(2), 187-195.

Nisbet, E. K., Zelenski, J. M., \& Murphy, S. A. (2008). The nature relatedness scale: Linking individuals' connection with nature to environmental concern and behavior. Environment and Behavior, 41(5), 715-740.

Pallant, J. (2013). SPSS survival manual: A step by step guide to data analysis using IBM SPSS (5th ed.). Milton Keynes, UK: Open University Press.

Robertson, M., Walford, R., \& Fox, A. (2003). Landscape meanings and personal identities: Some perspectives of East Anglian children. International Research in Geographical and Environmental Education, 12(1), 32-48.

Skår, M., \& Krogh, E. (2009). Changes in children's nature-based experiences near home: From spontaneous play to adult-controlled, planned and organised activities. Children's Geographies, 7(3), 339-354.

Veitch, J., Bagley, S., Ball, K., \& Salmon, J. (2006). Where do children usually play? A qualitative study of parents' perceptions of influences on children's active freeplay. Health \& Place, 12(4), 383-393.

Wells, N. M., \& Lekies, K. S. (2006). Nature and the life course: Pathways from childhood nature experiences. Children Youth and Environments, 16(1), 1-24.

Zhang, W., Goodale, E., \& Chen, J. (2014). How contact with nature affects children's biophilia, biophobia and conservation attitude in China. Biological Conservation, 177, 109-116.

Received: $1^{\text {st }}$ March 2019. Accepted: $26^{\text {th }}$ June 2019 